ISBN 978-81-933894-6-1

4th International Conference on Business, Education, Law and Interdisciplinary Studies

(BELIS-17)

London (UK) June 29-30, 2017

\title{
A Study of Consumer's Usage Experience and Re-Using Willingness of a Cultural and Historical Town "Sanxia" APP
}

\author{
Paoching $\mathrm{Chu}^{1}$, ChingChien Yang ${ }^{2}$,Chiahua Hsiao ${ }^{3}$ and Guan Chen ${ }^{4}$ \\ ${ }^{1}$ Assistant Professor, CCUT \\ ${ }^{2}$ Assistant Professor, CCUT \\ ${ }^{3}$ Assistant Professor, CCUT \\ ${ }^{4}$ Lecturer, CCUT
}

\begin{abstract}
Cultural Tourism" has become a part of modern life, since the advancement of social and economic changes, such as the economic prosperity, the increase of incomes, and the shorten of working hours, etc., which improve people's taste of life quality, and one's attitude toward working. Among all these old towns, Sanxia, nowadays a district in New Taipei City, is a historical and cultural district old town in North Taiwan. Founded on late Ming and early Qing dynasty, immigrants from China could go from Tamsui River straight to Sanxia by ships, and gather together into village. Therefore, a new tourist APP, combining the consumption electronic device, paper tourist guide and cultural information, is coming created. APP, meaning the application in short, is an application platform in the computer field. Since 2009, lots of application programs come into Android Market and grow rapidly. Therefore, this research focus on consumer's usage experience and re-usage willingness of the newly created Tourist Sanxia APP. And a questionnaire method is used, and totally 500 copies are distributed in this study.
\end{abstract}

KeyWords : Tourist Sanxia APP, Usage Experience, Trust, Re-using Willingness

\section{Introduction}

"Cultural Tourism" has become a part of modern life, since the advancement of social and economic changes, such as the economic prosperity, the increase of incomes, and the shorten of working hours, etc.,. The statistic data shows that foreign visitors rise from 3,519,827 in 2006 to 10,439,785 in 2015, and Taiwanese outbound tourists rise from 8,671,375 in 2006 to 13,182,976 in 2015. The Taiwanese Inbound tourist number rises gradually from 107,541,000 in 2006 to 178,524,000 in 2015.

Since the great advancement of inbound tourist economy and consumption electronic device, many tourists look for the information, such as attractions map and briefs, communication planning and time, etc., and record their traveling by hand-held mobile devices. The mobile guiding system provides users not only update information as well as breaking news, but also records management and personal comments. Then, these remarks can be shot, uploaded to cloud and shared with other users. There are many mobile guiding systems, such as Web, APP, QR Code, etc.

Sanxia, nowadays a district in New Taipei City, is a historical and cultural district old town in North Taiwan. Founded on late Ming and early Qing dynasty, immigrants from China could go from Tamsui River 
straight to Sanxia by ships, and gather together into village. During the colonization, the Japanese government forced to transform the local and traditional architectures into faked European façade on 1916, such as ancient Greek orders, ancient Roman arch, and Baroque decorations. Therefore, the architectures are mixed of European element style, Japanese kamon, and South Chinese cultural totem. The Sanxia Old Street, 200 meters long and preserved from the early $20^{\text {th }}$ century, are full of architectures of red South Chinese style of Bricks arch façade, which provokes an atmosphere of nostalgia. Therefore, Sanxia are therefore earned the Prix d Excellence Award of FIABCI, Barcelona, Spain, 2007.

To sum up, this research has 2 objectives: (1) Understanding the consumer's usage experience and re-using willingness of Sanxia APP. (2) Making some practical and academic suggestions to related industries from these findings.

\section{Literature Review}

\subsection{Hand-held Mobile Device and APP}

Since the great advancement of inbound tourist economy and consumption electronic device, many tourists look for the information, such as attractions map and briefs, communication planning and time, etc., and record their traveling by hand-held mobile devices. The mobile guiding system provides users not only update information as well as breaking news, but also records management and personal comments. Then, these remarks can be shot, uploaded to cloud and shared with other users. There are many mobile guiding systems, such as Web, APP, QR Code, etc. Besides, the top 5 of APP download are games, music and entertainments, community, communications and weather. It means that APP satisfies first of all most people needs of mobile leisure entertainments services, then the different kinds of needs in daily lives, such as map, weather, travel and food, etc. Due to APP's convenience and into life, the increase in popularity of smartphone and tablet computer will bring global APP industry outputs.

\subsection{Usage Experience}

Tsai (2012) pointed out one can know his design better if he has more consciousness of usage experiences and more sensitive to it. (1) You cannot tell the functions and operations immediately according to your past experiences of using similar products. Eve more, there are lots of differences from your used operations expected, and you need lots of practices in order to know the operations well. (2) It takes lots of time to learn how to use some new products, even though you learn very hard. (3) After learned how to use some new products, but you forget the operations easily during some extended period of time. (4) After learned how to use some new products, but it is not efficient to use them to do some routine works, such as the complexity of operation procedures, or the waiting time too long. (5) There are lots of operational errors of some new products, even you had used them for a long while, such as pressing the wrong button, or cannot find a menu, even worse that you must turn it off in order to reset it.

\subsection{Re-Using Willingness}

Consumer behavior is the sum of all brain activities explicit that a consumer looks for, buys, uses and evaluate some goods and services in order to meet his demands. Now we are entering an era of customer satisfaction and experiences due to the elevation of consumer rights and consciousness, therefore any business must highlight the importance of customer needs and satisfaction. Many researches pointed out that the customer dissatisfactions are inevitable during the service of after the service. If any business can not handle carefully these dissatisfactions or complains, these would cause more severe damages, such as customer loss or potential customer stagnation. ( $\mathrm{Yu}, \& \mathrm{Li}, 2016$ ) Therefore, there are 2 models of customer satisfaction in the world. Sweden Customer Satisfaction Barometer The Sweden Customer Satisfaction Barometer is the first 
national-wide model about customer satisfaction. It highlights a key point of Customer Satisfaction Elasticity, cited ci-below. There are 2 leading variables of customer satisfaction, that is customer perceived product or service value, and customer expectation toward product or service. Besides, there are also 2 outcome variables of customer satisfaction, customer complain and customer loyalty.

\section{Research Methodology}

\subsection{Sanxia APP Design Frame Work}

In this study, 5 steps of research methods are used (Figure 1).

\begin{tabular}{|c|}
\hline Data collecting of all sightseeing and stores \\
$\downarrow$ \\
\hline Check list of Tourist's choices of what to visit and not \\
$\downarrow$ \\
\hline Categorization of sightseeing and stores \\
$\downarrow$ \\
\hline Protocol of the Sanxia APP content \\
$\downarrow$ \\
\hline Test and feedback of APP content \\
\hline
\end{tabular}

Fig.1: APP Design Frame Work

\subsection{Research Sample, Validity and Reliability,}

First of all, an item analysis is executed in order to examine whether the all item's CR values significant or not. Second, the factor analysis is executed in order to examine the ball KMO and Bartlett's test. The results show that the cumulative amount of explained variance is $70.24 \%$. Third, the Cronbach's $\alpha$ coefficient of this questionnaire is $0.688 \sim 0.931$, which means this scale has good reliability.

\section{Research Findings}

\subsection{Introduction of Sanxia APP Design Frame Work}

There are 3 principles of designing the Sanxia APP contents, ie integration, convenience, and immediately. According to the check list, labeling results and categorization, Sanxia APP contents are divided into 3 levels: (1) Home page, (2) Categories, (3) Stores (Figure 2).

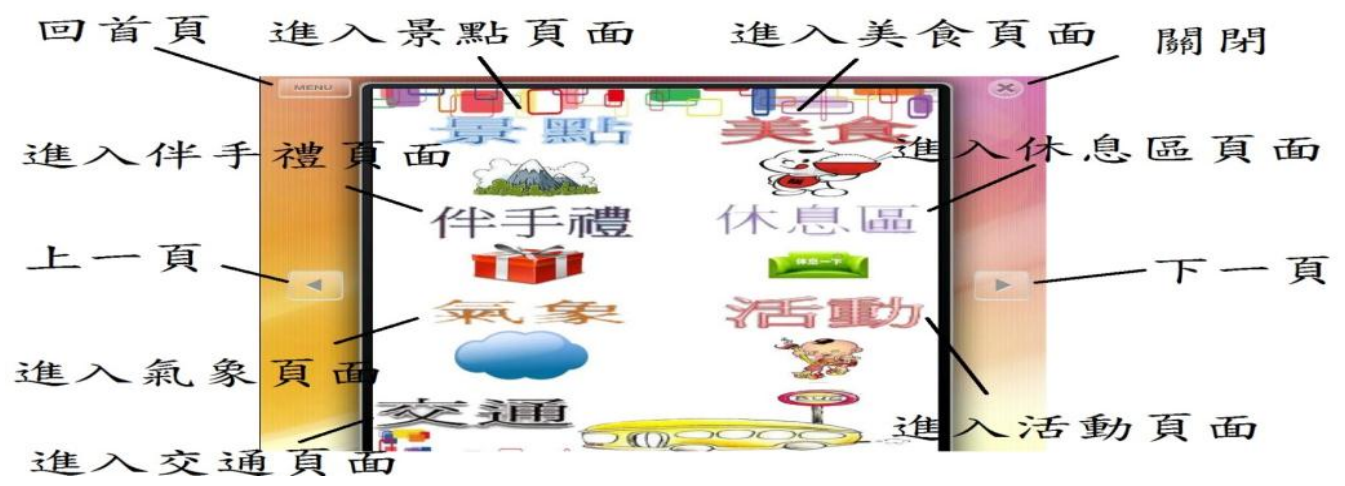

Fig. 2 The Function Page of Sanxia APP 


\subsection{Statistic Data Analysis}

\subsubsection{Sample Description}

After 3 months of work from Jan to March 2017, the study sample is shown in Table 1.

Table 1 Sample Description.

Table I Sample Description

$\mathrm{N}=362$

\begin{tabular}{|c|c|c|c|}
\hline Variables & Items & Sum & Percentage \\
\hline \multirow{2}{*}{ gender } & Male & 164 & 45.3 \\
& Female & 198 & 54.7 \\
\hline \multirow{2}{*}{ age } & Under 20 & 3 & .8 \\
& $21 \sim 30$ & 27 & 13.5 \\
& $31 \sim 40$ & 48 & 35.1 \\
& $41 \sim 50$ & 127 & 27.6 \\
& $51 \sim 60$ & 100 & 15.7 \\
\hline \multirow{2}{*}{ Education } & Over 60 & 57 & 1.7 \\
& Under high school & 6 & 14.9 \\
& High school & 54 & 68.0 \\
\hline
\end{tabular}

\subsubsection{Status Analysis}

The status analysis of Sanxia APP usage experience and reusing willingness is shown in Table II. The mean and standard deviance of usage experience and reusing willingness are respectively 3.94 / .50 and 3.96 / .68. Among all the items of usage experience, the score of "behavior" is highest, and "reflection" third. Among all the items of reusing willingness, the score of "recommendation" is highest, and "complain" third. It means that the consumer behavior toward Sanxia APP more on "recommendation" then "complains".

Table II: Status Analysis

$\mathrm{N}=362$

\begin{tabular}{ccccc}
\hline Variable & Component & Mean & SD & SUM \\
\hline Usage experience & instinct & 3.89 & 0.61 & $3.94 / .50$ \\
& behavior & 4.20 & 0.85 & \\
& reflection & 3.66 & 0.57 & $3.96 / 0.68$ \\
\hline \multirow{2}{*}{ Reusing willingness } & Complain & 3.22 & 0.86 & 0.69 \\
& Transfer & 3.65 & 0.45 & \\
\hline
\end{tabular}

\subsubsection{Difference Analysis}

The difference analysis between background variables and other variables is shown in Table III. In summary, (1) there are significant differences between all 3 background items (gender, age, and education) with usage experience. (2) there are significant differences between 3 background items (gender, age, and education) with 2 items of reusing willingness (complain and transfer). 
Table III: Difference Analysis

\begin{tabular}{cllc}
\hline Variables & Gender (T value) & Age (F value) & Education(F value) \\
\hline UE & $4.12^{*}$ & $13.99^{*}$ & $8.96^{*}$ \\
instinct & $4.52^{*}$ & $17.62^{*}$ & $10.41^{*}$ \\
behavior & $2.63^{* *}$ & $7.10^{*}$ & $12.85^{*}$ \\
reflection & $3.29^{*}$ & $9.11^{*}$ & 1.41 \\
RW & $2.09^{*}$ & $5.908^{*}$ & .90 \\
Complain & $2.35^{*}$ & $6.16^{* *}$ & $5.09^{* *}$ \\
Transfer & 2.30 & $5.39^{* *}$ & $4.89^{*}$ \\
Recommendation & 1.68 & .72 & .34 \\
\hline
\end{tabular}

$* \mathrm{P}<0.05 、 * * \mathrm{P}<0.01$

\subsubsection{Correlation Analysis}

A correlation analysis is shown in Table IV.

Table IV: Correlation Analysis

\begin{tabular}{lllllllll}
\hline V/I & UE & instinct & behavior & reflection & RW & Complain & Transfer & Recommdation \\
\hline $\mathbf{U E}$ & & & & &. & & & \\
instinct & $.51^{* *}$ & & & & & & & \\
behavior & $.56^{* *}$ & $.51^{* *}$ & & & & & & \\
reflection & $.10^{*}$ & $.56^{* *}$ & $.54^{* *}$ & & & & & \\
$\mathbf{R W}$ & $25^{* *}$ & $.13^{* *}$ & $.12^{* *}$ & $.23^{* *}$ & & & & \\
Complain & .06 & $.42^{* *}$ & $.33^{*}$ & .03 & $.54^{* *}$ & & & \\
Transfer & $.42^{* *}$ & $.53^{* *}$ & $.21^{*}$ & .00 & $.17^{* *}$ & $.33^{*}$ & & \\
Recommendation & $.33^{*}$ & $.17^{* *}$ & $.20^{* *}$ & .03 & $.13^{* *}$ & .07 & $.23^{* *}$ & \\
\hline
\end{tabular}

\subsubsection{Regression Analysis}

A regression analysis is proceeded and the result is shown in Table V and VI.

Table V Regression Analysis of Background Variable on Usage Experience

\begin{tabular}{c|cccc}
\hline $\begin{array}{c}\text { criteria variable } \\
\text { Predictor variable }\end{array}$ & instinct & $\begin{array}{c}\text { behavior } \\
\text { standardized regression coefficient }(\beta)\end{array}$ & UE \\
\hline BV & & & & \\
gender & $0.32^{*}$ & $0.26^{*}$ & $0.33^{*}$ & $0.32^{*}$ \\
age & $0.47^{*}$ & $0.49^{*}$ & $0.51^{*}$ & $0.47^{*}$ \\
education & 0.02 & 0.08 & 0.03 & 0.02 \\
\hline F value & $2.02^{*}$ & $1.87^{*}$ & $1.67^{* *}$ & $1.78^{* *}$ \\
R Square & 0.54 & 0.63 & 0.55 & 0.65 \\
\hline
\end{tabular}

$* \mathrm{p}<.05$

There is a positive predictable effect of background variable on usage experience, and a positive predictable effect of background variable on reusing willingness. 
Table VI: Regression Analysis of Background Variable on Reusing Willingness

\begin{tabular}{c|cccc}
\hline $\begin{array}{c}\text { criteria variable } \\
\text { Predictor variable }\end{array}$ & Recommendation & Transfer & Complain & RW \\
\hline BV & & & & \\
gender & $0.34^{*}$ & $0.18^{*}$ & $0.12^{*}$ & $0.19^{*}$ \\
age & $0.45^{*}$ & $0.40^{*}$ & $0.42^{*}$ & $0.43^{*}$ \\
education & $0.61^{*}$ & $0.31^{*}$ & $0.30^{*}$ & $0.54^{* *}$ \\
\hline F value & & $6.36^{*}$ & $18.54^{*}$ & $12.04^{*}$ \\
R Square & & 0.68 & 0.71 & 0.754 \\
\hline $\mathrm{p}<.05$ & & &
\end{tabular}

\section{Conclusion}

This study tries to put forward the following suggestions for small business owners : (1) The profile of this research is female, age 31 to 35 , education bachelor, occupation others, disposable amount 20k to 50k. (2) Among all the items of usage experience, the score of "behavior" is highest, "instinct" second, and "reflection" third. It means that the usage experience toward 3C product focuses more on "touch" instead of "thought". (3) Among all the items of consumer intention, the score of "service" is highest, "function" second, and "quality and reputations" third. It means that the consumer behavior toward 3C product focuses more on "service" instead of "price". (4) There are significant differences between all 5 background items (gender, age, education, occupation and disposable amount) with usage experience. Besides, there are significant differences between 4 background items (gender, age, occupation, and disposable amount) with consumer intention. (5) There is a positive predictable effect of background variable on usage experience, and a positive predictable effect of background variable on consumer intention. Besides, there is a positive predictable effect of Background Variable on Consumer Intention. Therefore, it is proved that usage experience is an intermediary variable between background variable and consumer intention.

\section{References}

[1] Brown J., Jounson R., \& Peter H., "Social Ties and Word-of-Mouth Referral Behavior," Journal of Consumer Research, Vol.14, pp.350-362, 1987.

[2] Chu, P. C. \& Chen, P. C.(2001), Affect working people's participation in decision-making factors MSc studies, Journal of 10(2): 1-14.

[3] Chu, P. C. Hsiao, J. H., Liu, Y. J., Hwang, C. H. \& Chen, P. Y. (2011), Taiwanese cosmetic products industry environment, research skills of the sales staff of professional and psychological, consumer patterns and sales staff to persuade, Journal of Chung Chou University of Technology and Science, 1(1): 15-30.

[4] Gaeth, G., Levin, I., Chakroborty, G. and Levin, A. "Consumer Evaluation of Multi-Product Bundles: An Information Integration Analysis,” Marketing Letters, Vol.2, No.1, pp.47-57, 1991.

[5] Holak, Susan L. and Lehmann, Donald R., "Purchase Intentions and the Dimensions of Innovation : an Exploratory Model,“ Journal of Product Innovation Management ,Vol.7, pp59-73,1990.

[6] Hwang S. T. , Cheng, C. J., Lin Y. T., Wu, M. H., Hwang T. J. \& Chi, I. C. (2010), A discussion of consumer buying factors: the example of 3C electronical devices, Journal of Industrial Technology and Education, 7(1): 106-125.

[7] Hwang Y. A., Chen Y. C., Chen, Y. J. \& Zan, S. W. (2006), Materialism, money attitude, vanity features, consumption I racism and product purchases Willingness Relationship, Journal of National Open University, 11: 
25-52.

[8] Lee, S. F. \& Chu, P. C. (2011), Study on the response of consumers to receive text messages advertising, Journal of Chung Chou University of Techology and Science, 1(1): 1-14.

[9] Lin, J. L. \& Yang, H. L. (2013), When people buy consumption electronical devices ? Date : 2013/12/25 ; http://www.inf.cyut.edu.tw/AIT2013/ft_086.pdf

[10] MBA(2013) $\circ$ Consumer behavior $\circ$ Date : 2013/11/28 ; http://wiki.mbalib.com/zh-tw/\%E6\%B6\%88\%E8\%B4\%B9\%E8\%A1\%8C\%E4\%B8\%BA

[11] Rogers, Everett M., Diffusion of Innovation, 3rd ed., New York : Free Press, 1983.

[12]Zeithaml, V. A. (1988) Consumer Perception of Price Quality, and Value: A means-end Model and Synthesis of Evidence, Journal of Marketing, vol.52, April, p.2-22 